\title{
GMR \\ Polymorphisms of GSTM1, GSTT1, and p53 in Goiânia, Goiás
}

\author{
D.A. Rodrigues ${ }^{1,2}$, I.R. Costa ${ }^{1,2,3}$, J.V.M. Martins ${ }^{1,2}$, K.S.F. e Silva ${ }^{4}$ and \\ K.K.V.O. Moura ${ }^{1,2,3}$ \\ ${ }^{1}$ Pontifícia Universidade Católica de Goiás, Goiânia, GO, Brasil \\ ${ }^{2}$ Núcleo de Pesquisa Replicon, Pontifícia Universidade Católica de Goiás, \\ Goiânia, GO, Brasil \\ ${ }^{3}$ Departamento de Biomedicina, Pontifícia Universidade Católica de Goiás, \\ Goiânia, GO, Brasil \\ ${ }^{4}$ Laboratório de Genética e Biologia Molecular, \\ Universidade Federal de Goiás, Goiânia, GO, Brasil \\ Corresponding author: K.S.F. e Silva \\ E-mail: smallbinho@hotmail.com
}

Genet. Mol. Res. 14 (4): 17358-17365 (2015)

Received November 19, 2014

Accepted July 30, 2015

Published December 21, 2015

DOI http://dx.doi.org/10.4238/2015.December.21.4

ABSTRACT. Genetic polymorphisms are defined as changes within the DNA sequences of genes that have frequencies in the population higher than $1 \%$. The glutathione $S$-transferases play an important role in the cellular detoxification systems involved in oxidative stress that can lead to accumulation of reactive oxygen species. Epidemiological studies have suggested that individuals with homozygous deletion of glutathione S-transferase mu 1 (GSTM1) and glutathione S-transferase theta 1 (GSTT1) are at higher risk of developing several types of neoplasias. The p53 protein is highly expressed in tumors and transformed cells, and the p53 is a classical tumor suppressor gene involved in regulating cell growth and development. In this study, we investigated the prevalence of polymorphisms in the p53, GSTM1, and GSTT1 genes in a population from Goiânia. We evaluated the polymorphisms of these genes in peripheral blood samples. The null or present polymorphism of GSTM1 and GSTT1 
genes and Arg/Pro of the p53 gene were analyzed. Our results revealed a higher frequency of the GSTM1-null polymorphism $(72.4 \%)$ than the GSTM1-present genotype (27.6\%). For GSTT1, we observed higher frequency for the null genotype (65.5\%) compared to the present genotype (34.5\%). Analysis of p53 gene polymorphisms showed a higher frequency for the genotype Arg/Pro (66\%) and a lower frequency for the Arg/Arg (23\%) and Pro/Pro (11\%) genotypes. It is essential to understand polymorphism frequencies in different populations and to evaluate the role of genetic polymorphisms and their effects on health.

Key words: Glutathione S-transferase mu 1; p53; Polymorphism; Glutathione S-transferase theta 1

\section{INTRODUCTION}

Polymorphisms are defined as variations within the DNA sequence of genes encoding certain enzymes. These changes give rise to altered proteins and consequently impair their activities and metabolic capacities. Polymorphisms show a frequency higher than $1 \%$ in the chromosomes of the general population (Willard, 2002).

Glutathione S-transferase (GST) is a family of proteins that play an essential role in the detoxification of exogenous and endogenous electrolytes that can promote the alkalization of DNA, leading to cellular dysfunction and toxicity. GSTs also catalyze other reactions such as the conversion of materials to organic hydrogen peroxide, which is crucial for protecting tissues against oxidative stress and nucleic acid damage (Sharma et al., 2000).

The genes encoding the isoenzymes GST theta 1 (GSTT1) and GST mu 1 (GSTM1) may exhibit null alleles as a result of gene deletion, leading to a reduction of their enzymatic activity. Epidemiological studies have suggest that individuals with homozygous deletion of GSTM1 and GSTT1 have a higher risk of developing several types of neoplasias (Morais et al., 2008). Variability in the phenotype distribution of null GSTM1 and GSTT1 genotypes has been reported in different populations, particularly in well-defined ethnic groups (Gattás et al., 2004).

The GSTM1 gene is located on chromosome $11 \mathrm{q} 13.3$, and approximately $20-50 \%$ of individuals expressing the mutated form are characterized by a homozygous deletion (when one or more nucleotides are deleted from the DNA sequence). GSTT1 is located on chromosome 22, and $20-60 \%$ of individuals have a deletion in this gene (Linhares et al., 2006).

Because of the importance of GST in the detoxification of electrophilic carcinogens, the null genotypes of GSTM1 and GSTT1 have been widely examined. Homozygous deletions result in a decreased carcinogen detoxification, thereby increasing the risk of developing several types of cancer including bladder, colon, lung, skin, and stomach cancers (Tsuang, 2004).

The p53 protein was first identified in 1979 in a study of Simian 40 virus and T antigen. This protein is highly expressed in tumors and transformed cells. p53 is a classical tumor suppressor gene involved in regulating cell growth and development (Papadakis et al., 2002). It is also known as the "guardian of the genome" because it has anti-proliferative effects that allow the preservation of the genetic information (Tada, 2001).

A particular p53 polymorphism is caused by the simple exchange of a purine by a pyrimidine base (CGC coding for arginine into CCC coding for proline), resulting in structural 
alteration of the protein (Thomas et al., 1999; Tada et al., 2001). Such variations may result in altered function because of changes in the protein conformation. This change can be detected by different migration patterns of electrophoresis and based on different biochemical and biological properties (Hamú, 2007).

Numerous studies have examined p53 in normal and neoplastic cell functioning, and these studies have examined many cell types. Altered protein p53 has been reported in several types of cancer, since adrenocortical tumors, leukemias, lymphomas, breast tumors, lung carcinomas, gastrointestinal, bone, and skin tumors (Viana, 2007).

In this study, we examined the prevalence of polymorphisms in the GSTM1, GSTT1, and p53 genes in a population from Goiânia, Brazil.

\section{MATERIAL AND METHODS}

We evaluated polymorphisms in 3 genes, GSTM1, GSTT1, and p53, in 442 peripheral blood samples. The null or present polymorphism in the GSTM1 and GSTT1 genes and Arg/Pro of the p53 gene were analyzed (Table 1). The samples were from patients who attended the Replicon Research Center from the population of Goiânia, state Goiás. All participants signed an informed consent form.

Table 1. Sequence of primers for GSTM1, GSTT1, p53, and ZFX/Y.

\begin{tabular}{|c|c|c|}
\hline Primer & Sequence & Molecular weight (bp) \\
\hline *GSTM1 & $\begin{array}{l}\text { F: 5'-ACCCCAGGGCTCTATGGGAA-3' } \\
\text { R: 5'-TGAGGGCACAAGAAGCCCTT-3' }\end{array}$ & 216 \\
\hline${ }^{*} G S T T 1$ & $\begin{array}{l}\text { F: 5'-TTCCTTACTGGTCCTCACATCTC-3' } \\
\text { R: 5'-TCACCGGATCATGGCCAGCA-3' }\end{array}$ & 480 \\
\hline "p53 Arg & $\begin{array}{l}\text { F: 5'-CTGGTGCAGGGGCCACGC-3' } \\
\text { R: 5'-CGTGCAAGTCACAGACTT-3' }\end{array}$ & 140 \\
\hline "p53 Pro & $\begin{array}{l}\text { F: 5'-GCCAGAGGCTGCTCCCCC-3' } \\
\text { R: 5'-ATCTACAGTCCCCCTTGCCG-3' }\end{array}$ & 177 \\
\hline$-Z F X / Y$ & $\begin{array}{l}\text { F: 5'-ACCRCTGTACTGACTGTGATTACTC-3' } \\
\text { R: 5'-GCACYTCTTTGGTATCYGAGAAAGT-3' }\end{array}$ & 495 \\
\hline
\end{tabular}

${ }^{*}$ Rohr et al., 2004; - Arruda et al., 2008; \#Silva, 2012.

In order to verify the presence of polymorphisms in GSTM1 and GSTT1, amplification was conducted. The absence of amplification indicated the null genotype, while amplification confirmed that the subject had at least one of the polymorphisms present. Analysis was performed in triplicate, and we only considered the null genotype after repeating the procedure 3 times, and all 3 trials showed the same results.

For the p53 gene we used two pairs of primers and the amplification means the presence of the polymorphism Arg/Arg, Pro/Pro, or Arg/Pro.

\section{Statistical analysis}

Genotypes of GSTM1, GSTT1, and p53 polymorphisms were compared using the chisquare test with the BioEstat software (version 5.0). 


\section{RESULTS}

Our results showed that the GSTM1-null polymorphism was more frequent $(72.4 \%$; $302 / 417)$ than the GSTM1-present genotype $(27.6 \% ; 115 / 417)$. The GSTT1 null genotype had a higher frequency $(65.5 \% ; 273 / 417)$ than the GSTT1 present genotype $(34.5 \% ; 144 / 417)$, as shown in Table 2.

Table 2. Frequency of GSTM1 and GSTT1 polymorphisms.
\begin{tabular}{lccccc}
\hline & & & GSTT1 \\
\cline { 2 - 5 } & $\mathrm{N}$ & GSTM1 & $\mathrm{N}$ & $\%$ & 34.5 \\
\hline Present & 115 & 27.6 & 144 & 65.5 \\
Null & 302 & 72.4 & 273 & 100.0 \\
Total & 417 & 100.0 & 417 & 0.03 \\
\hline
\end{tabular}

${ }^{*}$ Chi-square test.

Analysis of p53 gene polymorphisms showed a higher frequency for the Arg/Pro (66\%; 292/442) genotype and a lower frequency for the Arg/Arg (23\%; 102/442) and Pro/Pro (11\%; 48/442) genotypes (Figure 1).

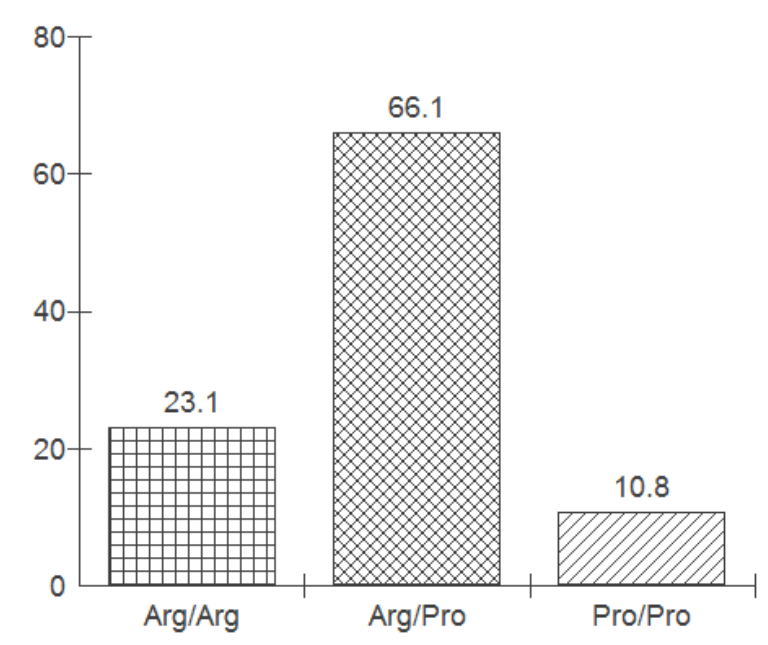

Figure 1. Frequency of genotypes Arg/Arg, Arg/Pro and Pro/Pro for the p53 gene. $P<0.0001$; chi-square test.

\section{DISCUSSION}

Genetic polymorphisms are genetic alterations that individually are not related to illnesses, are a variant of the normal genotype, and typically occur in a given population at a frequency higher than $1 \%$. Under certain environmental or physiological conditions, the associations between polymorphisms may increase the genetic susceptibility to different diseases (Tsuang, 2004).

Analysis of the prevalence of the GSTM1 polymorphism in a population from the state of Goiás showed that $72.4 \%$ of patients had the null genotype. Results from studies on the 
polymorphism of GSTM1 gene showed great variability within the country and worldwide. The highest prevalence was $75 \%$, found by Leme et al. (2010) in a population from São José do Rio Preto in the state of São Paulo. A lower prevalence (27.6\%) was reported by Chen et al. (1996) in the US. Other researchers detected a GSTM1-null polymorphism prevalence of $74.0 \%$ in women (Frare et al., 2013). Similar results showed that the GSTM1-null polymorphism was $73.8 \%$ in African-Americans (Weiserbs et al., 2003).

Other studies conducted in Brazil by Gattas et al. (2004) found a GSTM1-null polymorphism prevalence of $55.4 \%$ in Caucasians patients. Arruda et al. (1998) found a very similar prevalence of 55\% for the GSTM1-null genotype in Caucasian descendants in the state of São Paulo. Two different studies conducted in the US found prevalence rates of 53.5 and $50 \%$ for the GSTMT1 null polymorphism (Chen et al., 1996; Weiserbs et al., 2003), and the first study observed a higher prevalence in females. In the city of Porto Alegre, $50 \%$ of patients presented the GSTM1-null polymorphism (Kvitko et al., 2008).

The different frequencies found regarding the GSTM1-null genotype in different populations may be explained by the fact that there is large genetic variability among populations. Hatagima et al. (2000) observed frequencies of 48.6 and $46.4 \%$, respectively, for the GSTM1-null genotype in a population from Brasilia and Rio de Janeiro. Morais et al. (2008) found that $44.4 \%$ of the individuals analyzed in Campinas (São Paulo) carried the GSTM1-null genotype. In a study carried out in Bahia, they found that the GSTM1-null polymorphism was less prevalent $(43.9 \%)$ in that population. Arruda et al. (1998) and Gattas et al. (2004) found frequencies of 33.0 and $32.8 \%$, respectively, for the GSTM1-null polymorphism in a Brazilian black population.

Similarly to the studies examining the GSTM1 polymorphism, there is great variability in the GSTT1 null polymorphism. In our study, we observed that $65.5 \%$ of patients had the GSTT1 null genotype. Several studies support our results. Eshkoor et al. (2012) found a higher prevalence of the GSTT1 null genotype (62.5\%) in Malaysia. A lower prevalence was described by Nelson et al. (1995), and only $9.7 \%$ of Mexican-Americans analyzed in the city of Boston had the null polymorphism of the GSTT1 gene.

Based on the results of Nelson et al. (1995), the prevalence of the GSTT1 null polymorphism was $64.4 \%$ in Chinese patients and $60.2 \%$ in Koreans. Other studies also corroborate the results found in the present study, such those of Frare et al. (2013) who found a prevalence of $59 \%$ for the same genotype and Lee et al. (1995) who found a prevalence of $58.8 \%$ in Chinese patients.

The frequencies of the GSTT1 null genotype described for different ethnic groups vary considerably. In Singapore, for example, it was noted that $50 \%$ of the Caucasian population had the GSTT1 null polymorphism (Lee et al., 1995). A lower prevalence of the GSTT1 gene polymorphism was observed in Caucasian patients from Brazil in 2 different studies. Gattas et al. (2004) and Rossini et al. (2002) found that the frequencies of the GSTT1 null genotype were 25.1 and $22.3 \%$ of patients. A null GSTT1 prevalence of $21 \%$ was found in a study conducted in Serbia and $20.4 \%$ in the city of Boston; both studies analyzed Caucasian individuals (Nelson et al, 1995; Türkanoğlu et al, 2010). A previous study in the Brazilian population found a lower prevalence of the GSTT1 null polymorphism (18.5\%) in patients of the same ethnicity (Arruda et al., 1998) while Gonçalves et al. (2009) found a prevalence of $16.7 \%$ for the same polymorphism in patients from São Paulo.

When analyzing the GSTT1 null genotype in black patients, 2 studies conducted in Brazil found frequencies of 26.3 and 19.0\% (Arruda et al., 1998; Gattas et al., 2004). Regarding this same ethnical group Nelson and colleagues (1995) found a prevalence of $21.8 \%$ for the null GSTT1 polymorphism in patients from Boston (USA). 
Gattas et al. (2004) studied a population of patients from the Latin ethnic group and found that the GSTT1 null polymorphism prevalence was $17.2 \%$. Studies analyzing other populations found the following prevalence rates for the GSTM1-null polymorphism: $38 \%$ in Malays, $16 \%$ in Indians from Singapore (Lee et al., 1995), 15\% in North Americans, 14.7\% in Egyptians (Rahman et al., 1996), 13\% in Indians (Buch et al., 2001), and 11\% in Indians from Brazil (Arruda et al., 1998).

Polymorphisms in the p53 gene were detected a higher frequency for the genotype Arg/ Pro (66\%). Our results support the analysis performed by Neto (2007) in Pernambuco, where $71 \%$ of the samples analyzed were heterozygous for Arg/Pro. This study showed the highest prevalence of this polymorphism. Two different studies found prevalence rates of 64 and $50 \%$ for the heterozygous genotype Arg/Pro; the first study analyzed patients in Greece, while the second study was in Taiwan (Chen et al., 2002; Papadakis et al., 2002).

The frequency of homozygosity described in the present study was $23.1 \%$ for arginine and $10.8 \%$ for proline. Variability in the prevalence rates of the p53 genotypes were large. Hamú et al. (2007) found a prevalence of $70 \%$ for the genotype Arg/Arg in individuals from Goiânia. For the homozygous genotype Pro/Pro, Beckman et al. (1994) found a higher prevalence in the black population $(63 \%)$ than in Caucasians patients $(17 \%)$.

According to Pena (2005), in the Brazilian population there is a high degree of genetic miscegenation; therefore, characteristics such as physical appearance, skin color, eyes, hair, and shape of the lips and nose, are very poor indicators of the geographical origin of the ancestors of a given individual. Thus, the genetic variability of Brazilians is unique and includes individuals carrying mosaic genomes with different life histories. The Brazilian population presents a high degree of heterogeneity because of extensive interbreeding between European, African, and indigenous populations (Parra et al., 2003).

Studies conducted worldwide to examine GSTM1, GSTT1, and p53 are essential for evaluating the impact of genetic polymorphisms on health. Understanding polymorphism frequencies in different populations and evaluating the role of genetic polymorphism and their effects on health is important for using the polymorphism as biomarkers, which could lead to better diagnosis, prevention, and treatment strategies of several pathologies.

\section{Conflicts of interest}

The authors declare no conflict of interest.

\section{ACKNOWLEDGMENTS}

We thank Pontifical Catholic University of Goiás, Goiânia, Brazil (Replicon/Prope/MGene/ FAPEG/CNPq) for contributions and support that made this research possible.

\section{REFERENCES}

Arruda JT, Silva DM, Silva CC, Moura KKVO, et al. (2008). Homologous recombination between HERVs causes duplications in the AZFa region of men accidentally exposed to cesium-137 in Goiânia. Genet. Mol. Res. 14: 1063-1069.

Arruda VR, Grignolli CE, Gonçalves MS, Soares MC, et al. (1998). Prevalence of homozygosity for the deleted alleles of glutathione S-transferase umu (GSTM1) and theta (GSTT1) among distinct ethnic groups from Brazil: relevance to environmental carcinogenesis? Clin. Genet. 54: 210-214.

Beckman L, Birgander R, Själander A, Saha N, et al. (1994). Is p53 polymorphism maintained by natural selection? Hum. Hered. 44: 266-270. 
Buch S, Kotekar A, Kawle D and Bhisey R (2001). Polymorphisms at CYP and GST gene loci:prevalence in the Indian population. Eur. J. Clin. Pharmacol. 57: 553-555.

Chen CC, Hsieh YY, Tsai FJ, Tsai CH, et al. (2002). p21 gene codon 31 arginine/serine polymorphism(non-association with endometriosis. Fertil. Steril. 77: 43-45.

Chen CL, Liu Q and Relling MV (1996). Simultaneous characterization of glutathione S-transferase M1 and T1 polymorphisms by polymerase chain reaction in American whites and blacks. Farmacogenética 6: 187-91.

Eshkoor AS, Marashi SJ, Ismail P, Rahman AS, et al. (2012). Association of GSTM1 and GSTT1 with ageing in auto repair shop workers. Genet. Mol. Res. 11: 1486-1496.

Frare AB, Barbosa AM, Costa IR, Souza SR, et al. (2013). GSTM1 and GSTT1 polymorphisms in endometriosis. Genet. Mol. Res. 12: 2764-2770.

Gattás GFJ, Kato M, Soares-Vieira JA, Siraque MS, et al. (2004). GST polymorphism and ethnicity in Brazil. Braz. J. Med. Biol. Res. 37: 451-458.

Gonçalves AJ, Monte O, Morari EC, Ward LS, et al. (2009). Sistema glutation-s-transferase como fator prognóstico no carcinoma papilifero da tireoide. Rev. Assoc. Med. Bras. 55: 279-282.

Hamú CS, Oliveira MVP, Silva AMTC, Silva CCS, et al. (2007). Codon 72 polymorphism of the TP53 gene in patients suspected to have CML. Rev. Bras. Hematol. 29: 346-350.

Hatagima A, Guimaraes K, Nazaré M, Silva FP, et al. (2000). Glutathione S-transferase M1 (GSTM1) polymorphism in two Brazilian populations. Genet. Mol. Biol. 23: 709-713.

Kvitko K, Rohr P, Zucchetti G and Silla LMR (2008). Aspectos Ambientais e Genéticos no Desenvolvimento de Leucemias. Braz. J. Biosci. 6: 369-373.

Lee EJ, Wong JY, Yeoh PN and Gong NH (1995). Glutathione S transferase-theta (GSTT1) genetic polymorphism among Chinese, Malays and Indians in Singapore. Farmacogenética 5: 332-334.

Leme CVD, Raposo LSR, Ruiz MT, Biselli JM, et al. (2010). GstM1 and gstt1 genes analysis in head and neck cancer patients. Rev. Assoc. Med. Bras. 56: 299-303.

Linhares JJ, Silva IDCG, Noronha EC, Ferraro O, et al. (2006). Gene polymorphisms in the human progesterone receptor gene (PROGINS) and glutathione S-transferase (GST) and risk of breast cancer: a literature review. Rev. Bras. Cancerol.. 52: 387-393.

Morais LMTS, Filho CC, Lourenço GJ, Shinzato JY, et al. (2008). Características mamográficas do câncer de mama associadas aos polimorfismos GSTM1 E GSTT1. Rev. Assoc. Med. Bras. 54: 61-66.

Nelson HH, Wiencke JK, Christiani DC, Cheng TJ, et al. (1995). Ethnic differences in the prevalence of the homozygous deleted genotype of glutathione S-transferase theta. Carcinogênese 16: 1243-1245.

Neto AA (2007). Papilomavírus humano e o polimorfismo do códon 72 (Alelo-G) do gene TP53 no carcinoma escamoso oral/ Adauto Almeida Neto. Universidade Federal de Pernambuco, CCS. Patol. Geral Recife: O Autor.

Papadakis ED, Soulitzis N and Spandidos DA (2002). Association of p53 codon 72 polymorphism with advanced lung cancer: the Arg allele is preferentially retained in tumours arising in Arg/Pro germline heterozygotes. Br. J. Cancer 87: 1013-1018.

Parra FC, Amado RC, Lambertucci JR, Rocha J, et al. (2003). Color and genomic ancestry in Brazilians. Proc. Natl. Acad. Sci. U. S. A. 100: 177-82.

Pena SDJ (2005). Reasons for banishing the concept of race from Brazilian medicine. Hist. Cienc. Saúde-Manguinhos 12: 321-346.

Rahman ASZ, el-Zein RA, Anwar WA and Au WW (1996). A multiplex PCR procedure for polymorphic analysis of GSTM1 and GSTT1 genes in population studies. Cancer Lett. 107: 229-33.

Rossini A, Rapozo DCM, Amorin LMF, Macedo JMB, et al. (2002) Frequencies of GSTM1, GSTT1, and GSTP1 polymorphisms in a Brazilian population. Genet. Mol. Res. 1: 233-240.

Sharma R, Awasthi S, Zimniak P and Awasthi YC (2000).Transport of gluatatione-conjugates in human erythrocytes. Acta Biochim. Polonica 47: 751-762.

Tada M, Furuuchi K, Kaneda M, Matsumoto J, et al. (2001). Inactivate the remaining p53 allele or the alternate p73 Preferential selection on the Arg72 polymorphism in cancers with recessive p53 mutants but not transdominant mutants. Carcinogenesis 22: 515-517.

Thomas M, Kalita A, Labrecque S, Pim D, et al. (1999). Two polymorphic variants of wild-type p53 differ biochemically and biologically. Mol. Cell Biol. 19: 1325-8.

Tsuang MT, Bar JL, Stone WS and Faraone SV (2004). Gene-environment interactions in mental disorders. World Psychiatr. 3: 73-83.

Türkanoğlu A, Can DB, Demirkaya S, Bek S, et al. (2010). Association analysis of GSTT1, GSTM1 genotype polymorphisms and serum total GST activity with ischemic stroke risk. Neurol. Sci. 6: 727-34.

Viana DA (2007). Polimorfismo do gene TP53 no linfoma de hodgkin/Daniel de Araújo Viana. - Fortaleza, 84 f.:I1. 
Weiserbs KF, Jacobson JS, Begg MD, Wang LW, et al. (2003). A cross-sectional study of polycyclic aromatic hydrocarbon-DNA adducts and polymorphism of glutathione S-transferases among heavy smokers by race/ethnicity. Biomarkers 8:142-55. Willard H (2000). Genética e Câncer. In: Genética médica Thompson \& Thompson (Nussubaum RL, Mcinnes RR and Huntingt FN, eds.). Guanabara Koogan, Rio de Janeiro, 274-293. 